\title{
Thyroid lymphoproliferative lesions in Asia
}

\section{Tripti Nakra, Deepali Jain, Shipra Agarwal}

Department of Pathology, All India Institute of Medical Sciences, New Delhi, India

Contributions: (I) Conception and design: S Agarwal; (II) Administrative support: None; (III) Provision of study materials or patients: None; (IV) Collection and assembly of data: T Nakra; (V) Data analysis and interpretation: T Nakra, S Agarwal; (VI) Manuscript writing: All authors; (VII) Final approval of manuscript: All authors.

Correspondence to: Shipra Agarwal, MD. Associate Professor, Department of Pathology, All India Institute of Medical Sciences, New Delhi 110029, India. Email: drshipra0902@gmail.com.

\begin{abstract}
Primary thyroid lymphomas (PTLs) are rare and most commonly present as rapidly enlarging thyroid mass causing obstructive symptoms. Due to worldwide differences in clinical practices related to thyroid malignancy, this review was conducted to compare the clinicopathological and diagnostic modalities related to PTL and their similarities and differences between the Asian and Western countries. Using the search engine PubMed, published data on thyroid lymphomas was collected and reviewed. A total of 18 Asian and 22 Western studies were included. Most of PTLs were B-cell Non-Hodgkin lymphomas (NHL). While mucosa-associated lymphoid tissue (MALT) lymphoma was the commonest (41.1\%) among Asians, diffuse large B cell lymphoma (DLBCL) (71.9\%) predominated in the Western population. Some rare subtypes of PTL were also identified. Majority of all patients in Asian as well as Western studies presented with early stage (stage I/II) disease. Interestingly, when compared with Asian patients, a larger proportion of patients from the West presented with higher stage (stage III/IV) disease (12.2\% vs. 3\%). Ultrasonography (USG) and fine needle aspiration cytology (FNAC) in addition to histological examination usually by core needle biopsy and in some by open procedures were used for the diagnosis of PTL in both the cohorts. The various ancillary techniques used were immunocytochemistry (ICC), flowcytometry (FC), immunohistochemistry (IHC), and molecular testing. The use of ancillary techniques for PTL diagnosis was more common in the West compared to Asia and markedly increased the sensitivity of cytology to diagnose PTL. Treatment and prognosis largely depend upon the subtype of PTL and stage at presentation. To conclude, from the available published literature, there is an apparent difference between Asian and Western cohorts in the histological type and stage of presentation of PTL, but the results may be affected by publication and selection bias. Also, advanced ancillary techniques are more commonly adopted in the West.
\end{abstract}

Keywords: Asia; cytology; flowcytometry (FC); immunocytochemistry (ICC); thyroid lymphoma; West

Submitted Apr 01, 2020. Accepted for publication Jul 04, 2020.

doi: $10.21037 / g s-20-432$

View this article at: http://dx.doi.org/10.21037/gs-20-432

\section{Introduction}

Primary lymphomas of thyroid are rare and account for $1-5 \%$ of all thyroid malignancies (1) and $1-2 \%$ of extranodal lymphomas (2). Primary thyroid lymphoma (PTL) is defined as a lymphoma which involves the thyroid gland with or without the involvement of regional neck lymph nodes; but without the contiguous spread or distant metastases from other areas of involvement at the time of diagnosis (3). These are more common in females and present in sixth to seventh decades of life (4). Although the normal thyroid gland is devoid of any native lymphoid tissue PTL often arises in a background of Hashimoto thyroiditis (HT) with the relative risk of 67 as compared to those without thyroiditis (5). The chronic antigenic stimulation leads to accumulation of genetic abnormalities and proliferation of abnormal $\mathrm{B}$-cell clones giving rise to lymphoma (1). Most of the PTLs are Non-Hodgkin 
lymphomas (NHL) of B-cell type with diffuse large B-cell lymphoma (DLBCL) being the most common subtype followed by mucosa-associated lymphoid tissue (MALT) lymphoma (4). Ultrasonography (USG) is usually the initial modality for the diagnosis of thyroid lesions. However, pathological confirmation and subtyping of lymphoma is essential. Fine needle aspiration cytology (FNAC) is a useful, effective and well-established technique for evaluation of thyroid swellings. But low sensitivity of FNAC for detecting thyroid lymphoma questions its diagnostic accuracy especially for MALT lymphoma where distinction from HT may be challenging. Since PTLs are sensitive to chemotherapy and radiotherapy, accurate diagnosis using minimally invasive tools is crucial to obviate the need for unnecessary resections and allow for early treatment. The use of ancillary techniques for immunophenotyping using immunohistochemistry (IHC)/immunocytochemistry (ICC)/flow cytometry (FC) can greatly aid in diagnosing difficult cases (6). Various studies have been published in literature addressing the diagnostic issues related to thyroid lymphomas. Herein we review all the available data regarding the clinicopathological characteristics, methods used for the diagnosis and treatment of PTL. The main focus of this review is comparison of diagnostic approach and practices being followed by the Asian and Western countries in management of PTL.

\section{Methods}

An internet-based literature search was conducted for the published work on PTL using PUBMED. All the original articles pertaining to both histology and cytology where full text was available were reviewed. Case reports, case series, review articles, and conference proceedings were excluded. Cross references of the included studies were also checked for additional studies. In case of more than one study from the same institute with overlapping time period, and possibility of overlapping data, study with larger cohort was included. The cytology results wherever available including their category as per 'The Bethesda system for reporting thyroid cytopathology' (TBSRTC) were recorded (7). Prevalence of specific PTL subtypes was calculated as a proportion of number of cases of that subtype reported in literature to the total number of PTL cases reported. The prevalence of patients in a particular clinical stage was also calculated similarly. Data from studies which were limited to a specific subtype of PTLs was excluded from final analysis to calculate proportions.

\section{Results and discussion}

A total of 40 studies fulfilled the inclusion and the exclusion criteria, detailing 2,928 PTL cases (Table 1) including some studies which were based on specific subtypes of PTL $(17,39,44)$.

\section{Clinical presentation}

Clinical presentation was similar across Asian and Western studies. The most common (75-85\%) presenting symptom of PTL is rapidly growing thyroid mass $(19,23,38,46)$, and can mimic anaplastic thyroid carcinoma (47). Other symptoms include hoarseness of voice, dysphagia, dyspnea or stridor as a result of compression due to mass (48). Presence of neck lymphadenopathy is variable. A proportion of patients (5-20\%) may also present with B-symptoms like fever, night sweats and weight loss $(18,28,42)$. A history of HT may be there as risk of developing PTL is $40-80$ times higher in these patients (48). In a study by Mizokami et al., all 9 patients of HT developed MALT lymphoma during 3-18 years of USG follow up (15).

The staging of PTL is based on Ann Arbor staging criteria similar to staging of other lymphomas (47). The reported data in literature (wherever available) regarding the staging of PTL from Asian and Western cohorts, has been depicted and compared in Table 2.

While most cases (97\% in Asia and $87.8 \%$ in West) presented as either stage I or stage II disease, a smaller proportion (3\% in Asia and $12.2 \%$ in West) had stage III or stage IV disease. The apparent difference in proportion of patients presenting in higher stage in West may be attributed to the proportion of DLBCL cases in the Western cohort (71.9\% in West vs. 37.3\% in Asia).

\section{Prevalence and spectrum/classification of PTL}

Reported prevalence of PTL was similar in Asian $(11,12)$ and Western studies $(27,28,30,34,35)$ (Table 2). MALT lymphoma and DLBCL are the most common histological subtypes of PTL (Table 2). Interestingly, of all the PTLs, while DLBCL was the most frequent $(71.9 \%$; including DLBCL transformed from low-grade NHL) subtype in western literature, MALT lymphoma was the commonest (41.1\%) in Asian studies. Some recent studies have subclassified DLBCL into germinal and post-germinal center type $(12,14,18,26)$. Other rare subtypes of PTL reported include follicular lymphoma (FL), chronic 
Table 1 Review of published literature on thyroid lymphomas

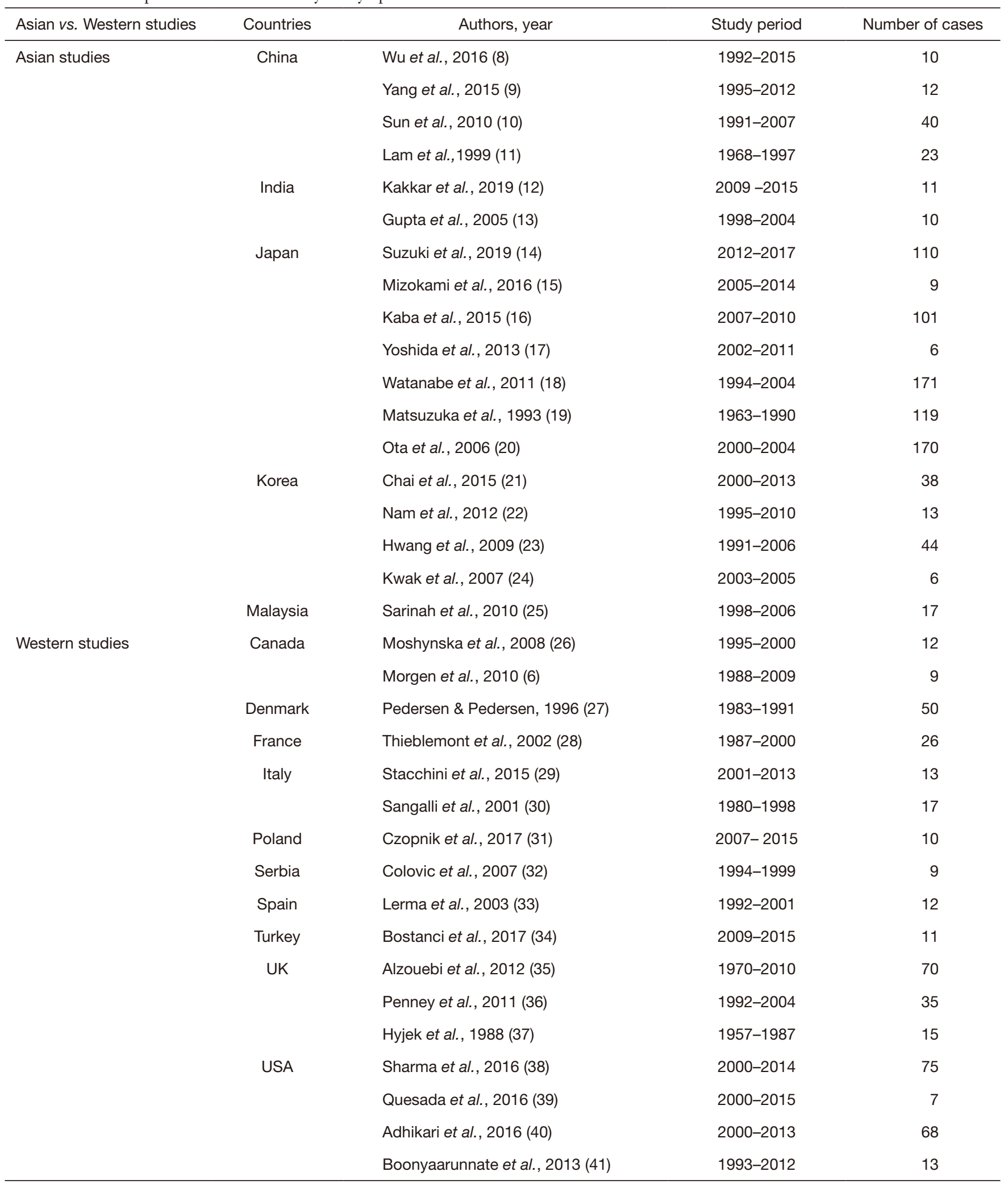

Table 1 (continued) 
Table 1 (continued)

\begin{tabular}{|c|c|c|c|c|}
\hline Asian vs. Western studies & Countries & Authors, year & Study period & Number of cases \\
\hline & & Ruggiero et al., 2005 (43) & $1977-2004$ & 22 \\
\hline & & Wang et al., 2005 (44) & 1990-2005 & 5 \\
\hline & & Cha et al., 2002 (45) & $1985-2000$ & 23 \\
\hline
\end{tabular}

lymphocytic leukemia/small lymphocytic lymphoma (CLL/ SLL) (40,42), Burkitt lymphoma (BL) (39), mantle cell lymphoma (MCL) (42), Hodgkin lymphoma (HL) (44), plasmacytoma (42) and NHL of T-cell origin $(17,38)$ (Table 2).

\section{Diagnostic modalities}

\section{Imaging}

USG, although not specific, is the initial modality of choice for the screening of thyroid masses. The USG findings in PTL are mostly based on internal echoes, border of the lesion and posterior echoes. These features classify the lesions detected on USG into nodular type, diffuse type and mixed type as observed in many studies $(9,15,20)$. In all these types, it has been found that PTLs are predominantly hypoechoic masses $(9,22)$ and show enhancement of posterior echoes $(9,20)$. These hypoechoic areas correspond to lymphoepithelial lesions of PTL (22). The positive predictive value (PPV) of detecting lymphoma is $63-65 \%$ in cases of nodular or mixed type and these can mimic follicular lesion or adenomatous goiter. However diffuse type is difficult to differentiate from chronic thyroiditis where around $62 \%$ cases can be misdiagnosed as PTL (20). USG has been used as a pre-treatment modality in PTL management in both Asian and Western studies.

\section{FNAC}

FNAC is a valuable and widely accepted diagnostic tool for evaluating thyroid masses. The use of TBSRTC is recommended for categorizing thyroid cytology worldwide however, in thyroid lymphoma cases except for one Asian study (12), none of the studies have used TBSRTC for categorizing aspirates. This observation may be attributed to the reason that most of these studies were conducted before the introduction of TBSRTC.
In a recent study from Japan, of the 107 patients of MALT lymphoma, $79 \%$ cases could be diagnosed as thyroid lymphoma by FNAC (2). In other Asian studies dealing with smaller number of cases, the diagnostic rate of thyroid lymphoma on FNAC was 50-90\% (10,13,23,24). Interestingly, none of the nine cases in the study by Wu et al. could be diagnosed as NHL on cytology, and this was attributed to the lack of adequate experience of cytopathologists for the diagnosis of rare diseases (8). In contrast to DLBCL, false negative rates are high among MALT lymphoma or low-grade NHL which can be misdiagnosed as lymphocytic thyroiditis because of the presence of large numbers of heterogeneous cells and the concurrent presence of HT or due to sampling error (48). Selective aspiration of reactive lymphoid follicles of HT may be misinterpreted as "atypical lymphoid cells", as also reported in two studies $(2,40)$, but none of them reported it as "suspicious for" or "diagnostic of" lymphoma. Liquidbased cytology (LBC) smears were prepared in three of the Western studies $(6,40,44)$ and in none of the included Asian studies. A study from Asia compared the cytomorphology of PTL on LBC with that of conventional smears. This study was not included in the analysis in this review because of overlapping study period with another study published from the same institute (14). The authors reported that on LBC large elongated swollen nuclei act as a clue to differentiate PTL from non-neoplastic lymphoid cells and that lymphoglandular bodies are not reliable for diagnosing PTL (49).

Although studies from both Asia and West have documented the utility of FNAC in initial evaluation of PTL (Table 3), the diagnostic rate in West was $65-100 \%$ $(6,29,30,38,40)$, similar to that reported in Asian studies $(6,19,29,30,40,45)$.

\section{Surgical biopsies}

FNAC can be used for definite diagnosis or suggesting 
Table 2 Prevalence and clinicopathological distribution of primary thyroid lymphomas

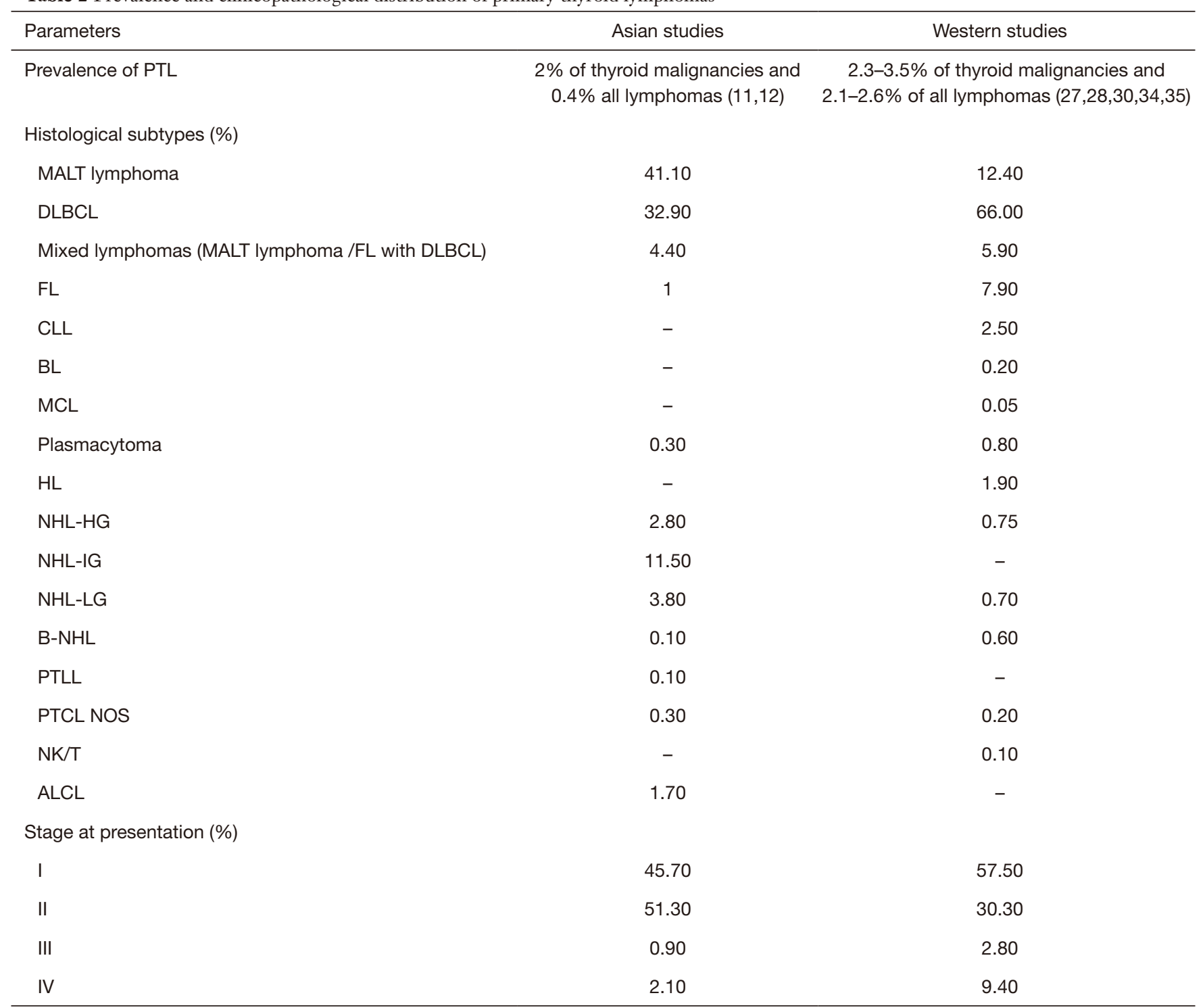

PTL, Primary thyroid lymphoma; MALT, Mucosa-associated lymphoid tissue; FL, follicular lymphoma; CLL, chronic lymphocytic leukemia; BL, Burkitt lymphoma; MCL, mantle cell lymphoma; HL, Hodgkin lymphoma; NHL, Non-Hodgkin lymphoma; HG, high grade; IG, intermediate grade; LG, low grade; PTLL, primary T-cell lymphoblastic lymphoma; PTCL NOS, primary T-cell lymphoma, not otherwise specified; NK/T, NK/T cell lymphoma; ALCL, anaplastic large cell lymphoma.

a diagnosis of PTL, but confirmation and subtyping requires tissue biopsy, core needle biopsy $(\mathrm{CNB})$ being the most common modality. In lymphomas per se CNB can successfully classify histological subtypes in $89.7 \%$ of neck lymphomas (50). For PTL, CNB has shown an overall sensitivity of $87-93 \%$ compared to $50-71 \%$ with FNAC $(38,51)$. CNB has been proven to be superior predominantly in diagnosing MALT lymphoma and has $100 \%$ sensitivity compared to lower sensitivity of FNAC (25\%) (38). The accurate diagnosis and exact characterization of PTL using $\mathrm{CNB}$ can avoid unnecessary surgical interventions.

Open surgical procedures (wedge biopsy/resection) were also performed in some studies $(6,8,10,12-15,22-25,27$, $30-32,34-36,38,41-46)$. The reasons for this procedure varied from non-diagnostic CNB results $(8,25)$ or served as a therapeutic/debulking procedure or to relieve obstructive symptoms or associated pain $(10,22,25,31,35,38)$. On evaluating corresponding available cytology details of these 


\begin{tabular}{|c|c|c|}
\hline Ancillary techniques & Asian studies (18) & Western studies (22) \\
\hline Liquid-based cytology & 0 & $3(13.6)$ \\
\hline \multicolumn{3}{|l|}{ Immunocytochemistry } \\
\hline Smears & $2(11.1)$ & $2(9.1)$ \\
\hline Immunohistochemistry & $4(22.2)$ & $8(36.4)$ \\
\hline Flowcytometry & $3(16.7)$ & $7(31.8)$ \\
\hline Southern blot & $2(11.1)$ & 0 \\
\hline EBER-ISH & $1(5.6)$ & $2(9.1)$ \\
\hline FISH & 0 & $1(4.5)$ \\
\hline
\end{tabular}

Data present as n (\%). EBER-ISH, Epstein-Barr encoding region-in situ hybridization; FISH, fluorescence in-situ hybridization; PCR, polymerase chain reaction.

cases $(6,8,10,12,13,15,22-25,30-32,34,38,41,43-45)$, it was found that the cytological spectrum encompassed the entire spectrum of TBSRTC categories including one case of follicular neoplasm (25).

\section{Ancillary techniques}

ICC is helpful for diagnosis and subtyping of PTL using cytology material. Limited ICC can be performed on cytology smears. Although some studies used LBC for cytological evaluation $(6,40,44)$, none of the studies have specified use of LBC for ICC. Cell blocks (CB) permit application of a more extensive ICC panel, and are particularly popular in the Western countries (Table 3). Even a basic panel of CD 3 and CD 20 performed on $\mathrm{CB}$ has been reported to be useful in diagnosing PTL $(29,30,40)$. Using this limited panel, Sangalli et al., in 2001, could correctly identify NHL in $90 \%$ of their cases; one case showed T-cell predominance and was labeled as HT. This false negative case was attributed to sampling error as MALT lymphoma along with HT was confirmed on followup thyroidectomy specimen (30). Stacchini et al., also used ICC on CB. Of the 13 cases, 11 could be diagnosed as NHL and two cases were called suspicious for NHL (29). No such data of ICC on CB has been reported from Asia, though there are studies in which ICC was performed on cytology smears for PTL diagnosis $(10,13)$.

Immunohistochemistry is commonly applied on surgical biopsy or on specimen of thyroidectomy, if resected; the advantage being the elaborate panel which can be applied due to more available tissue. Its utility and results have been documented both in Asian $(9,11,12,18)$ and Western studies (26-28,32,39,43,44,46).

Flowcytometry (FC) is a reliable method for evaluation of patients suspected to have PTL. The National Cancer Institute (NCI)-sponsored Thyroid Fine Needle Aspiration State of the Science Conference concluded that FC is useful for immunophenotyping of clinically suspected cases of PTL (52), as has also been documented in some Asian and Western studies $(14,15,17,28,29,39-41,43,45)$. Hirokawa et al. tried to establish a diagnostic algorithm based on findings of USG, FNAC and FC. They aimed at identifying monoclonal population of lymphoid cells with light chain restriction by $\mathrm{CD} 45$ gating using $\mathrm{FC}$ and defined it as $\kappa / \lambda$ light chain ratios of greater than $3: 1$ or less than $1: 3$. They found that $25 \%$ cases of PTL were missed and nearly $11 \%$ cases of HT showed light chain restriction. But still the sensitivity and specificity of FC (75\% and $88.4 \%)$ was much more than FNAC alone (59.4\% and 41.9\%) (53). Mizokami 
et al. used FC for assessment of monoclonality (15). Another study focused on Primary peripheral T-cell lymphoma (PTCL) of thyroid also used FC, however further details have not been provided in the published work (17).

Of the western studies, an extensive panel of antibodies was used for immunophenotyping in two $(29,41)$, while the other three studies $(39,40,45)$ used a limited panel of B/ T- cell along with light chains. The remaining two studies $(28,43)$ did not discuss the panel of antibodies used in FC analysis.

Cha et al. compared the diagnostic rate of FNA in pre and post era of immunophenotyping and found that FC significantly impacted the ability to correctly identify lymphoma on FNAC (45). FC can increase sensitivity and specificity of cytology to diagnose PTL to $100 \%$ (29) obviating the need for a diagnostic surgical biopsy $(41,45)$.

Cytology sample obtained by FNA is the most commonly used material for FC, and was used by most authors. Tissue samples obtained by trucut biopsy, wedge biopsy or thyroidectomy may also be used. As the cells need to be suspended in liquid medium, additional processing is required for tissue specimens, like homogenization of sample, which is more time consuming and labour intensive; and can result in reduction of viable cells. Thus, FNAC samples are considered superior to tissue specimens for FC analysis. However, resection specimens provide the advantage of histologic correlation which is lacking with FNA (54). Two studies, one from the USA (43) and the other from Japan (14) have documented use of tissue samples in FC for PTL management. While the former used frozen specimens for FC (43), the latter have just mentioned resection specimens as the material used (14). Suzuki et al. performed FC on a large number of aspirated and resected materials and found nearly similar detection rates $(73.7 \%$ and $69.2 \%$ respectively) of light chain restriction from both types of materials (14).

Molecular testing: use of molecular methods as an ancillary technique in PTL diagnosis and management has also been discussed in some studies $(11,14,15,17,26,28,29$, $39,40,43,44,46)$, more commonly in those from the West (Table 3). Majority of these methods were performed from surgical tissue specimens except two studies where FNA material was used $(29,40)$.

Polymerase chain reaction (PCR) has also been used in PTL for assessment of monoclonality or identification of gene rearrangement $(15,26,29,40,43)$. A rare case of primary T-cell lymphoblastic lymphoma diagnosed on FC was confirmed by identification of T-cell receptor (TCR) rearrangement without undergoing biopsy (29). In another study, $\operatorname{IgH}$ gene sequences were analyzed to test the hypothesis of PTL arising in a background of HT (26).

Cytogenetic analysis for characteristic translocations have been used in rare subtypes of PTL like $t(8 ; 14)$ in BL, $\mathrm{t}(14 ; 18)$ in FL and $\mathrm{t}(11 ; 14)$ in MCL, all documented in Western literature $(28,40,46)$. A study from Asia reported karyotypic analysis using G-banding chromosomal examination and documented chromosomal aberrations in $49.0 \%$ of PTLs including abnormalities like addition, trisomy, and deletions besides translocations. The unique observation by these authors was that none of the MALT lymphoma cases showed any of the four translocations $\mathrm{t}(1 ; 14)(\mathrm{p} 22 ; \mathrm{q} 32), \mathrm{t}(11 ; 18)(\mathrm{q} 21 ; \mathrm{q} 21), \mathrm{t}(14 ; 18)(\mathrm{q} 32 ; \mathrm{q} 21)$, and $\mathrm{t}(3 ; 14)(\mathrm{p} 14 ; \mathrm{q} 32)$ known to be associated with MALT lymphomas. They suggested that this discrepancy may be due to cytogenetic differences between MALT lymphomas arising in the thyroid and other organs (14). However, a recent study from Germany documented presence of $\mathrm{t}(11 ; 18)(\mathrm{q} 21 ; \mathrm{q} 21)$ in one of the two low grade thyroid MALT lymphomas evaluated by cytogenetics. The second case harbored multiple aberrations. Four cases of high-grade MALT lymphoma were also analyzed, and showed complex chromosomal clones (55). Another study from Austria demonstrated presence of $\mathrm{t}(3 ; 14)$ (p14;q32) in 3 of the 6 cases of thyroid MALT lymphoma assessed (56).

Cytogenetic analysis has also been used to detect genetic alterations in PTCL-NOS of thyroid (17). Yoshida et al. studied six cases of PTCL-NOS associated with autoimmune thyroiditis, and found loss of $6 \mathrm{q} 24.2$ in four. None showed genomic alterations previously reported for PTCL-NOS. The authors, hence, suggested that primary PTCL-NOS of the thyroid arising from autoimmune thyroiditis may be a distinct entity among PTCL-NOS (17).

Southern blot analysis for molecular testing was used in two Asian studies to detect TCR gene rearrangement in PTCL, NOS involving the thyroid gland (17) and to assess IgH rearrangement in PTLs (14), respectively. The incidence of $\mathrm{IgH}$ rearrangement documented in the latter study was lower in MALT lymphoma (58.1\%) compared to DLBCL and FL (100\%) (14).

The association between EBV and lymphomas is wellknown, but still its detection for diagnostic reasons in PTL is uncommon, due to rarity of EBV-associated BL and HL in thyroid. One of the studies from China has analyzed EBV gene expression using in-situ hybridization (ISH) and IHC against EBV-LMP1, EBNA-2 and ZEBRA 
protein (11). Among the 19 thyroid lymphomas tested in this study, one primary DLBCL and one secondary BL were found to be positive with EBER-ISH. However, in two studies from USA, EBER-ISH was used for diagnostic workup in cases of BL and HL $(39,44)$. One of these two studies also used fluorescence in-situ hybridization for the detection of $M Y C$ gene rearrangement in BL (39). Similar data is lacking from Asian studies.

\section{Treatment and prognosis}

Histology and stage of the tumor play an important role in deciding management protocol, the latter being similar across the World. The role of surgery in PTL has declined in the recent years and is limited mostly as palliative measure in patients presenting with obstructive symptoms $(10,22,25,31,35,38,48)$. Although optimal management of PTL is still controversial, multimodality treatment is considered as treatment of choice. For localized indolent lymphomas like MALT or FL, locoregional control of disease is achieved by either surgery or radiotherapy alone or in combination (47). For aggressive or disseminated PTLs, combination of chemotherapy and radiotherapy has been proven to be effective for control of disease and improving the outcome (35). The standard regimen of chemotherapy is a combination of cyclophosphamide, doxorubicin, vincristine, and prednisone (CHOP). The 5 -year overall survival rate ranges from $35 \%$ to $100 \%$ (35). MALT lymphoma and DLBCL of thyroid gland have been reported to have better prognosis and survival rates when compared to other extra-nodal and nodal sites $(2,57)$.

\section{Limitations of the study}

Considering the retrospective nature, presence of publication and selection bias is contemplated.

\section{Conclusions}

PTLs are rare malignancies. They have a similar clinical presentation across the World, though the available literature hinted towards a larger proportion of cases in the Western cohort presenting with diffuse large B cell lymphoma as well as higher stage disease. These results, however, may be impacted by publication and selection bias. Although pre-treatment USG and aspiration cytology are routinely used worldwide as routine screening and diagnostic measures, ancillary techniques like LBC, immunocytochemistry, FC and molecular analysis, are much more commonly used in the West.

\section{Acknowledgments}

Funding: None.

\section{Footnote}

Provenance and Peer Review: This article was commissioned by the Guest Editor (Kennichi Kakudo) for the series "Asian and Western Practice in Thyroid Pathology: Similarities and Differences" published in Gland Surgery. The article was sent for external peer review organized by the Guest Editor and the editorial office.

Peer Review File: Available at http://dx.doi.org/10.21037/gs$20-432$

Conflicts of Interest: All authors have completed the ICMJE uniform disclosure form (available at http:// dx.doi.org/10.21037/gs-20-432). The series "Asian and Western Practice in Thyroid Pathology: Similarities and Differences" was commissioned by the editorial office without any funding or sponsorship. The authors have no other conflicts of interest to declare.

Ethical statement: The authors are accountable for all aspects of the work in ensuring that questions related to the accuracy or integrity of any part of the work are appropriately investigated and resolved.

Open Access Statement: This is an Open Access article distributed in accordance with the Creative Commons Attribution-NonCommercial-NoDerivs 4.0 International License (CC BY-NC-ND 4.0), which permits the noncommercial replication and distribution of the article with the strict proviso that no changes or edits are made and the original work is properly cited (including links to both the formal publication through the relevant DOI and the license). See: https://creativecommons.org/licenses/by-nc-nd/4.0/.

\section{References}

1 Zhang L, Castellana M, Virili C, et al. Fine-needle aspiration to diagnose primary thyroid lymphomas: A systematic review and meta-analysis. Eur J Endocrinol 2019;180:177-87. 
2 Watanabe N, Narimatsu H, Noh JY, et al. Long-Term outcomes of 107 cases of primary thyroid mucosaAssociated lymphoid tissue lymphoma at a single medical institution in Japan. J Clin Endocrinol Metab 2018;103:732-9.

3 Sakorafas GH, Kokkoris P, Farley DR. Primary thyroid lymphoma: Diagnostic and therapeutic dilemmas. Surg Oncol 2010;19:e124-9.

4 Stein SA, Wartofsky L. Primary thyroid lymphoma: A clinical review. J Clin Endocrinol Metab 2013;98:3131-8.

5 Holm LE, Blomgren H, Löwhagen T. Cancer risks in patients with chronic lymphocytic thyroiditis. N Engl J Med 1985;312:601-4.

6 Morgen EK, Geddie W, Boerner S, et al. The role of fineneedle aspiration in the diagnosis of thyroid lymphoma : A retrospective study of nine cases and review of published series. J Clin Pathol 2010;63:129-33.

7 Cibas ES, Ali SZ. The 2017 Bethesda System for Reporting Thyroid Cytopathology. J Am Soc Cytopathol 2017;6:217-22.

8 Wu SY, Chu CH, Duh QY, et al. Management for primary thyroid lymphoma: Experience from a single tertiary care centre in Taiwan. Formos J Surg 2016;49:201-7.

9 Yang L, Wang A, Zhang Y, et al. 12 cases of primary thyroid lymphoma in China. J Endocrinol Invest 2015;38:739-44.

10 Sun TQ, Zhu XL, Wang ZY, et al. Characteristics and prognosis of primary thyroid Non-Hodgkin's lymphoma in Chinese patients. J Surg Oncol 2010;101:545-50.

11 Lam KY, Lo CY, Kwong DLW, et al. Malignant lymphoma of the thyroid: A 30-year clinicopathologic experience and an evaluation of the presence of Epstein-Barr virus. Am J Clin Pathol 1999;112:263-70.

12 Kakkar A, Purkait S, Agarwal S, et al. Primary thyroid lymphoma: A series from a tertiary care center in Northern India. J Cancer Res Ther 2019;15:669-75.

13 Gupta N, Nijhawan R, Srinivasan R, et al. Fine needle aspiration cytology of primary thyroid lymphoma: A report of ten cases. Cytojournal 2005;2:21.

14 Suzuki A, Hirokawa M, Higashiyama T, et al. Flow cytometric, gene rearrangement, and karyotypic analyses of 110 cases of primary thyroid lymphoma: a single-institutional experience in Japan. Endocr J 2019;66:1083-91.

15 Mizokami T, Hamada K, Maruta T, et al. Development of primary thyroid lymphoma during an ultrasonographic follow-up of Hashimoto's thyroiditis: A report of 9 cases. Intern Med 2016;55:943-8.
16 Kaba S, Hirokawa M, Higuchi M, et al. Cytological findings for the diagnosis of primary thyroid mucosaassociated lymphoid tissue lymphoma by fine needle aspiration. Acta Cytol 2015;59:26-36.

17 Yoshida N, Nishikori M, Izumi T, et al. Primary peripheral T-cell lymphoma, not otherwise specified of the thyroid with autoimmune thyroiditis. Br J Haematol 2013;161:214-23.

18 Watanabe N, Noh JY, Narimatsu H, et al. Clinicopathological features of 171 cases of primary thyroid lymphoma: A long-term study involving 24553 patients with Hashimoto's disease. Br J Haematol 2011;153:236-43.

19 Matsuzuka F, Miyauchi A, Katayama S, et al. Clinical aspects of primary thyroid lymphoma: Diagnosis and treatment based on our experience of 119 cases. Thyroid 1993;3:93-9.

20 Ota H, Ito Y, Matsuzuka F, et al. Usefulness of ultrasonography for diagnosis of malignant lymphoma of the thyroid. Thyroid 2006;16:983-7.

21 Chai YJ, Hong JH, Koo DH, et al. Clinicopathological characteristics and treatment outcomes of 38 cases of primary thyroid lymphoma: A multicenter study. Ann Surg Treat Res 2015;89:295-9.

22 Nam M, Shin JH, Han B, et al. Thyroid lymphoma: Correlation of radiologic and pathologic features. J Ultrasound Med 2012;31:589-94.

23 Hwang YC, Kim TY, Kim WB, et al. Clinical characteristics of primary thyroid lymphoma in Koreans. Endocr J 2009;56:399-405.

24 Kwak JY, Kim EK, Ko KH, et al. Primary thyroid lymphoma: role of ultrasound-guided needle biopsy. J Ultrasound Med 2007;26:1761-5.

25 Sarinah B, Hisham AN. Primary lymphoma of the thyroid: Diagnostic and therapeutic considerations. Asian J Surg 2010;33:20-4.

26 Moshynska OV, Saxena A. Clonal relationship between Hashimoto thyroiditis and thyroid lymphoma. J Clin Pathol 2008;61:438-44.

27 Pedersen RK, Pedersen NT. Primary non-Hodgkin's lymphoma of the thyroid gland: A population based study. Histopathology 1996;28:25-32.

28 Thieblemont C, Mayer A, Dumontet C, et al. Primary thyroid lymphoma is a heterogeneous disease. J Clin Endocrinol Metab 2002;87:105-11.

29 Stacchini A, Pacchioni D, Demurtas A, et al. Utility of flow cytometry as ancillary study to improve the cytologic diagnosis of thyroid lymphomas. Cytometry B Clin Cytom 
2015;88:320-9.

30 Sangalli G, Serio G, Zampatti C, et al. Fine needle aspiration cytology of primary lymphoma of the thyroid: A report of 17 cases. Cytopathology 2001;12:257-63.

31 Czopnik P, Aporowicz M, Niepokój-Czopnik A, et al. Primary thyroid lymphoma: A rare but challenging diagnosis. Pol Arch Intern Med 2017;127:361-4.

32 Colović M, Matić S, Kryeziu E, et al. Outcomes of primary thyroid non-Hodgkin's Lymphoma. Med Oncol 2007;24:203-8.

33 Lerma E, Arguelles R, Rigla M, et al. Comparative findings of lymphocytic thyroiditis and thyroid lymphoma. Acta Cytol 2003;47:575-80.

34 Bostanc1 H, Dikmen K, Akyürek N, et al. Eleven patients with primary thyroid lymphoma: A single center experience. Turk J Med Sci 2017;47:1322-7.

35 Alzouebi M, Goepel JR, Horsman JM, et.al Primary thyroid lymphoma: The 40 year experience of a UK lymphoma treatment centre. Int J Oncol 2012;40:2075-80.

36 Penney SE, Homer JJ. Thyroid lymphoma: Acute presentation and long-term outcome. J Laryngol Otol 2011;125:1256-62.

37 Hyjek E, Isaacson PG. Primary B cell lymphoma of the thyroid and its relationship to Hashimoto's Thyroiditis. Hum Pathol 1988;19:1315-26.

38 Sharma A, Jasim S, Reading CC, et al. Clinical presentation and diagnostic challenges of thyroid lymphoma: A cohort study. Thyroid 2016;26:1061-7.

39 Quesada AE, Liu H, Miranda RN, et al. Burkitt lymphoma presenting as a mass in the thyroid gland: A clinicopathologic study of 7 cases and review of the literature. Hum Pathol 2016;56:101-8.

40 Adhikari LJ, Reynolds JP, Wakely PE. Multi-institutional study of fine-needle aspiration for thyroid lymphoma. J Am Soc Cytopathol 2016;5:170-6.

41 Boonyaarunnate T, Olson MT, Ali SZ. Impact of flow cytometry in thyroid cytopathology. Acta Cytol 2013;57:562-6.

42 Graff-Baker A, Roman SA, Thomas DC, et al. Prognosis of primary thyroid lymphoma: Demographic, clinical, and pathologic predictors of survival in 1,408 cases. Surgery 2009; 146:1105-15.

43 Ruggiero FP, Frauenhoffer E, Stack BC. Thyroid lymphoma: A single institution's experience. Otolaryngol Head Neck Surg 2005;133:888-96.

44 Wang SA, Rahemtullah A, Faquin WC, et al. Hodgkin's lymphoma of the thyroid: A clinicopathologic study of five cases and review of the literature. Mod Pathol 2005;18:1577-84.

45 Cha C, Chen H, Westra WH, et al. Primary thyroid lymphoma: Can the diagnosis be made solely by fineneedle aspiration? Ann Surg Oncol 2002;9:298-302.

46 Derringer GA, Thompson LDR, Frommelt RA, et al. Malignant lymphoma of the thyroid gland: A clinicopathologic study of 108 cases. Am J Surg Pathol 2000;24:623-39.

47 Graff-Baker A, Sosa JA, Roman SA. Primary thyroid lymphoma: A review of recent developments in diagnosis and histology-driven treatment. Curr Opin Oncol 2010;22:17-22.

48 Walsh S, Lowery AJ, Evoy D, et al. Thyroid lymphoma: Recent advances in diagnosis and optimal management strategies. Oncologist 2013;18:994-1003.

49 Suzuki A, Hirokawa M, Ito A, et al. Identification of cytological features distinguishing Mucosa-Associated Lymphoid Tissue Lymphoma from reactive lymphoid proliferation using thyroid liquid-based cytology. Acta Cytol 2018;62:93-8.

50 Huang PC, Liu CY, Chuang WY, et al. Ultrasoundguided core needle biopsy of cervical lymphadenopathy in patients with lymphoma: The clinical efficacy and factors associated with unsuccessful diagnosis. Ultrasound Med Biol 2010;36:1431-6.

51 Ha EJ, Baek JH, Lee JH, et al. Core needle biopsy could reduce diagnostic surgery in patients with anaplastic thyroid cancer or thyroid lymphoma. Eur Radiol 2016;26:1031-6.

52 Filie AC, Asa SL, Geisinger KR, et al. Utilization of Ancillary Studies in Thyroid Fine Needle Aspirates : A Synopsis of the National Cancer Institute Thyroid Fine Needle Aspiration State of the Science Conference. Diagn Cytopathol 2008;36:438-41.

53 Hirokawa M, Kudo T, Ota H, et al. Preoperative diagnostic algorithm of primary thyroid lymphoma using ultrasound, aspiration cytology, and flow cytometry. Endocr J 2017;64:859-65.

54 Boyd JD, Smith GD, Hong H, et al. Fine-needle aspiration is superior to needle core biopsy as a sample Acquisition method for flow cytometric analysis in suspected hematologic neoplasms. Cytometry B Clin Cytom 2015;88:64-8.

55 Ott G, Katzenberger T, Greiner A, et al. The t $(11 ; 18)$ (q21;q21) chromosome translocation is a frequent and specific aberration in low-grade but not high-grade malignant non-Hodgkin's lymphomas of the mucosa- 
associated lymphoid tissue (MALT) type. Cancer Res 1997;57:3944-8.

56 Streubel B, Vinatzer U, Lamprecht A, et al. T(3;14) (p14.1; 32 ) involving IGH and FOXP1 is a novel recurrent chromosomal aberration in MALT lymphoma.

Cite this article as: Nakra T, Jain D, Agarwal S. Thyroid lymphoproliferative lesions in Asia. Gland Surg 2020;9(5):18271837. doi: $10.21037 /$ gs-20-432
Leukemia 2005;19:652-8.

57 Costa LJ, Xavier AC. Features and outcomes of diffuse large B-cell lymphoma of the thyroid in a large contemporary cohort. Leuk Lymphoma 2014;55:283-7. 